\title{
SÍNTESE DE ESTRUTURAS METALORGÂNICAS (MOFS) E SUA APLICAÇÃO NO PROCESSO DE CAPTURA E ARMAZENAMENTO DE GASES
}

\author{
V. H. S. LIMA', G. A. GIL', G. O. LIMA', L. M. PEDRO'1, P. A. ARROYO², J. G. \\ MENEGUIN $^{2}$ e M. P. MOISES ${ }^{1}$ \\ ${ }^{1}$ Universidade Tecnológica Federal do Paraná campus Apucarana, Departamento de \\ Engenharia Química \\ ${ }^{2}$ Universidade Estadual de Maringá, Departamento de Engenharia Química \\ E-mail para contato: murilomoises@utfpr.edu.br
}

RESUMO - O acúmulo de gás carbônico na atmosfera tornou o ponto de partida para a síntese de um material poroso com o intuito de adsorver quantidades significavas deste gás presente no ar. A estrutura metal orgânica UIO-66 foi desenvolvida para que possa atender a esses problemas com eficiência e sem grande custo ou dificuldades de produção.

\section{INTRODUÇÃO}

As mudanças climáticas e as catástrofes ocorridas em meados do século XX e XXI geraram várias polêmicas sobre a existência do aquecimento global. Alguns pesquisadores defendem que ações antrópicas interferem nas condições do planeta, enquanto outros afirmam que a Terra passa por um ciclo de aquecimento e resfriamento, assim como na época da glaciação.

Desse modo, sem ter uma resposta concreta sobre o tal fato, deu-se origem a várias alternativas para diminuir o impacto ambiental. Uma importante e carente área de pesquisa é a captura de gases de efeito estufa (GEE). Estes, são compostos que absorvem a radiação refletida ou emitida pela superfície terrestre. Sem os GEEs, seria impossível a manutenção da vida no planeta Terra, pois estima-se uma temperatura de $33^{\circ} \mathrm{C}$ menor do que a atual, ou seja, a temperatura média do globo estaria em torno de $15^{\circ} \mathrm{C}$ negativos, o que inviabilizaria vida no mesmo. De acordo com Houghton et al. (2013), o quinto relatório do Painel Intergovernamental sobre Mudanças do Clima (IPCC - AR5), as concentrações dos dois principais gases de efeito estufa - metano $\left(\mathrm{CH}_{4}\right)$, e dióxido de carbono $\left(\mathrm{CO}_{2}\right)$ - tiveram um grande aumento desde 1750.

O Brasil possui uma Política Nacional de Mudanças Climáticas com uma meta de redução de emissões de $36,1 \%$ para 2028. Uma série de ações está em curso para o país atingir essas metas, incluindo um conjunto de planos descentralizados em áreas como combate ao desmatamento, agricultura, indústria, energia, transportes e mineração.

A soma de todas essas preocupações e objetivos a serem alcançados, deu espaço às técnicas de captura e a separação de $\mathrm{CO}_{2}$ que dentre as principais são: processo de absorção, 
separação por membrana e adsorção em sólidos. Muitas pesquisas têm o objetivo de sintetizar novos adsorventes de $\mathrm{CO}_{2}$, eficazes, seletivos e de baixo custo.

Dentre os materiais mais utilizados como adsorventes aplicados ao processo de captura de $\mathrm{CO}_{2}$, destacam-se: zeólitas, sílica mesoporosas, carvão ativadoestruturas metalorgânicas (MOFs), polímeros reticulados e óxidos metálicos. Neste cenário, existe um crescente interesse em MOFs, devido à possibilidade de funcionalização (que possibilita o aumento da seletividade na separação de gases) e alta área específica destes materiais.

Yaghi et al. (2003) divulgaram novos materiais nanoestruturados, denominados de MOF's ("Metal Organic Framework") ou polímero de coordenação. Essa série de nanoestruturas possui no centro um íon metálico coordenado com moléculas orgânicas (ligantes) ao redor, como mostrado na Figura 1.

Figura 1 - Organização estrutural de MOFs em geral.

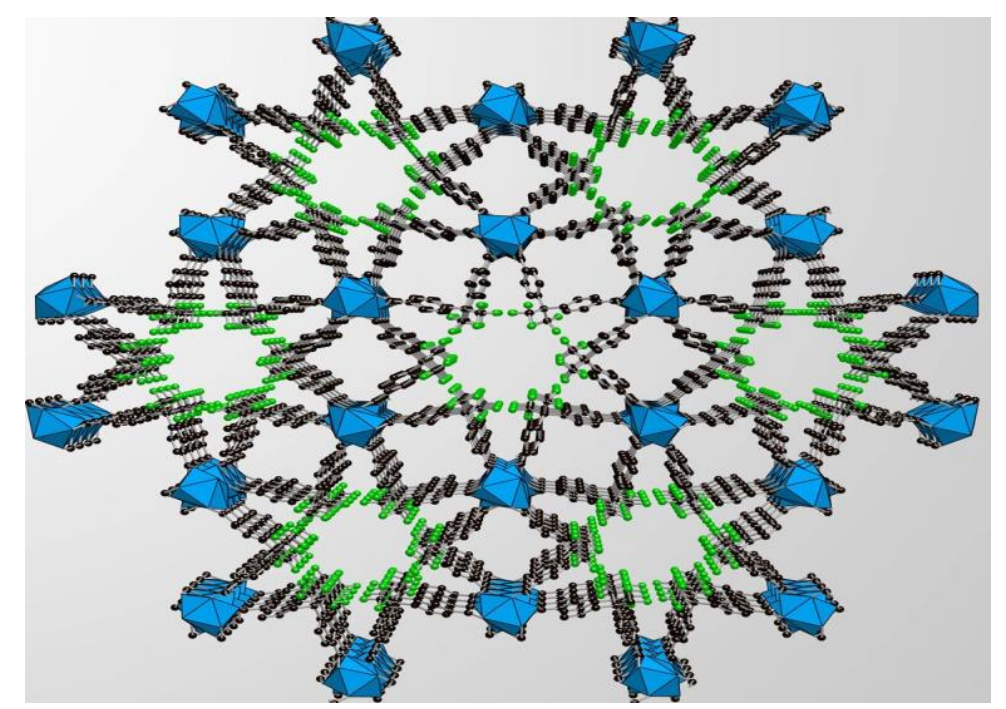

Essa estrutura de metal-ligante se repete formando uma estrutura polimérica de complexos metálicos. Suas características de alta estabilidade, estruturas cristalinas bem definidas, elevada área específica (entre 500 a $7500 \mathrm{~m}^{2} \mathrm{~g}^{-1}$ ) e vasta funcionalidade devido à escolha do ligante orgânico e íon metálico, esses materiais têm se destacado há alguns anos com uma importante junção entre a ciência de materiais e a química sintética.

Entretanto, os estudos sobre MOFs vêm crescendo constantemente e atingem aplicações em armazenamento de gases, catálise, liberação de fármacos, fases estacionárias para cromatografia, entre várias outras.

Contudo, a exemplo disso é o composto metalorgânico UIO-66 que foi reportado por Cavka et al. (2008) via síntese solvotérmica, utilizando cloreto de zircônio e ácido tereftálico. Este composto é formado por clusters de zircônio octacoordenados $\left(\mathrm{Zr}_{6} \mathrm{O}_{4}(\mathrm{OH})_{4}\right)$ em que, cada cluster está conectado a outros 12 clusters via ligantes tereftalato, em estrutura cúbica de face centrada, como apresentado na Figura 2. 
Figura 2 - (a) Conjunto de óxido de zircônio octacoordenado; (b) Célula unitária do UIO-66.

(a)

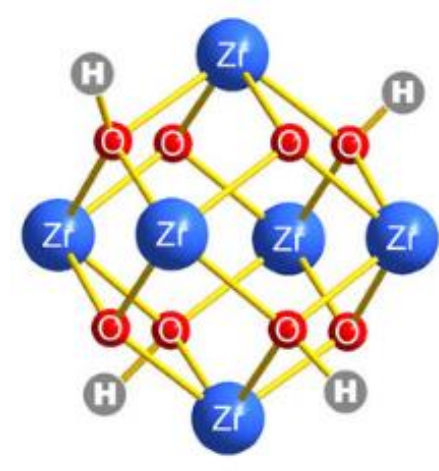

(b)

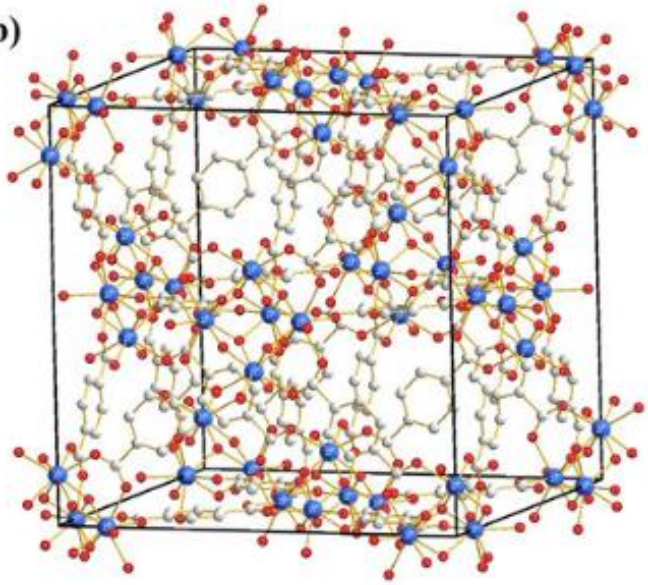

Segundo Wu et al. (2013), Cliffe et al. (2014) e Cavka et al. (2008) existem nesta estrutura dois tipos de cavidades, uma octaédrica de diâmetro de 11 A e outra tetraédrica com diâmetro de 8 A. O UIO-66 apresenta grande estabilidade térmica e química, além de grande área específica. Tais peculiaridades permitem aplicações em processos de captura e separação de gases.

\section{MÉTODO E PROCEDIMENTO}

Neste trabalho, será sintetizado e caracterizado um material para aplicação no processo de remoção e captura de $\mathrm{CO}_{2}$.

\subsection{Preparação do UIO-66}

Inicialmente foi obtido duas amostras de composto metalorgânico UIO-66 através do tratamento solvotérmico a $80^{\circ} \mathrm{C}$, em que a primeira foi permanecida por um tempo de 12 horas, enquanto a segunda por 24 horas. Utilizou-se ácido tereftálico como ligante orgânico e oxicloreto de zircônio. Ambos são adicionados, com razão molar de 1:2, à um balão de fundo redondo acoplado em um sistema de refluxo com $45 \mathrm{~mL}$ de N,N - dimetilformamida (DMF) junto com $3 \mathrm{~mL}$ de ácido clorídrico. O material resultante foi filtrado e lavado com $20 \mathrm{~mL}$ de DMF, imerso em $50 \mathrm{~mL}$ de metanol por 24 horas. Por fim, a substância foi separada por filtração e seco à $25^{\circ} \mathrm{C}$ por mais 24 horas.

A caracterização do material foi feita por difração de raios $X$ através do DRX Shimadzu XRD 6000, utilizando cobre (1.5418 ̊̊) como fonte de radiação. A velocidade de varredura foi de 2 graus a cada minuto com passo de $0,01^{\circ}$, voltagem de $40 \mathrm{kV}$ e corrente elétrica de $40 \mathrm{~mA}$. A fisissorção de $\mathrm{N}_{2}$ à $-196^{\circ} \mathrm{C}$ (ASAP 2020 - Ativação da amostra a $300^{\circ}$ $\mathrm{C}$ por 4 horas) e adsorção de $\mathrm{CO}_{2}$ e $\mathrm{N}_{2}$ à $25^{\circ} \mathrm{C}$ (ASAP 2020).

\section{RESULTADOS E DISCUSSÕES}


Os resultados do DRX, da fisissorção de $\mathrm{N}_{2}$ e adsorção de $\mathrm{CO}_{2}$ e $\mathrm{N}_{2}$ à $25{ }^{\circ} \mathrm{C}$ são mostrados respectivamente nos itens (a), (b) e (c) na Figura 3.

Figura 3 - (a) Difratogramas de raios X para as amostras sintetizadas por $12 \mathrm{~h}$ e $24 \mathrm{~h}$; (b) Isoterma de fisissorção de $\mathrm{N}_{2}$ para a amostra UIO-66-12 h após ativação térmica a $300{ }^{\circ} \mathrm{C}$; (c) Isotermas de adsorção de $\mathrm{CO}_{2}$ e $\mathrm{N}_{2}$ a $25^{\circ} \mathrm{C}$ e a relação entre as quantidades adsorvidas.
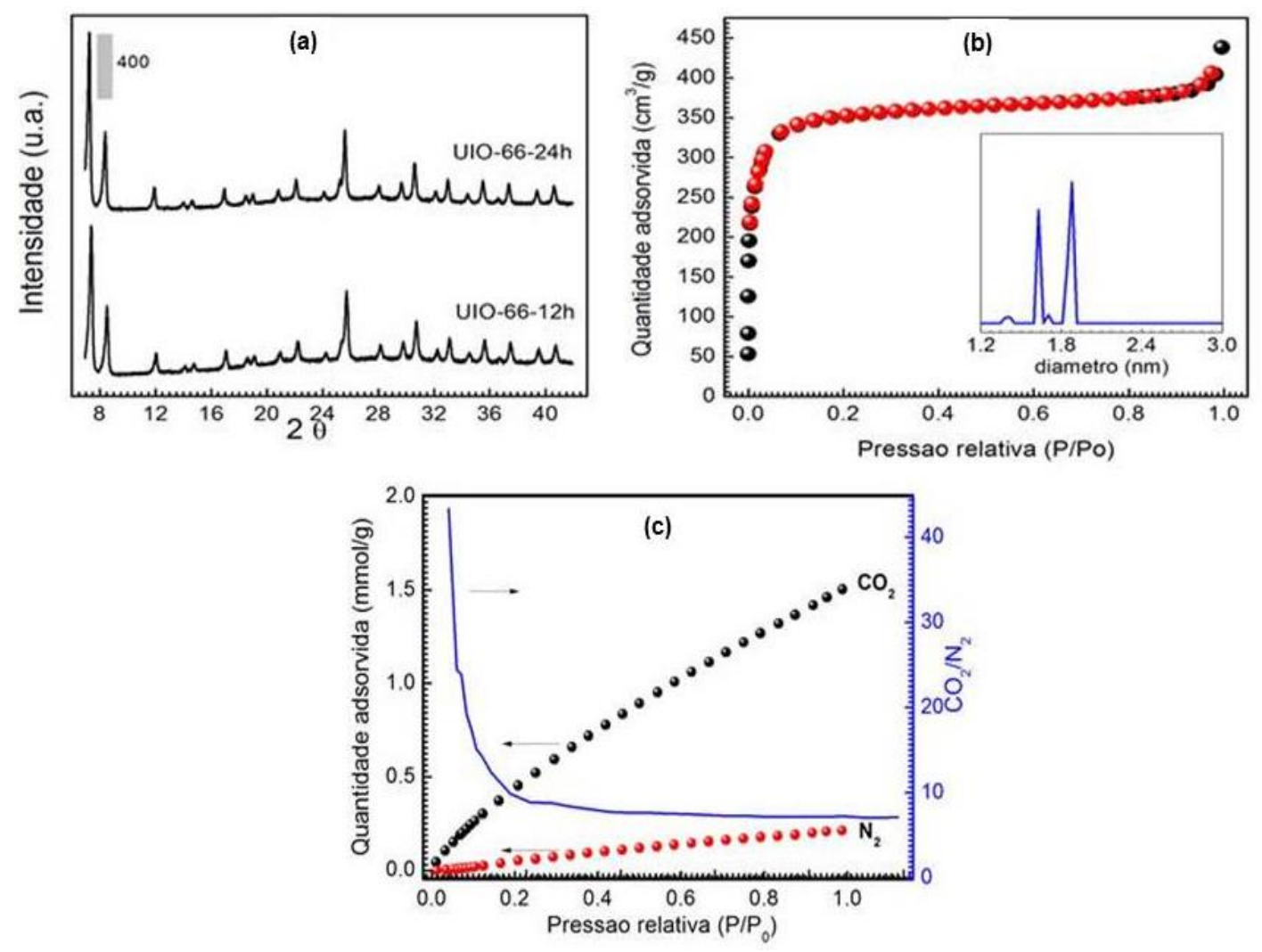

Tanto as amostras sintetizadas por 12 horas e 24 horas foram comparadas através do difratogramas de raios $\mathrm{X}$ e todos os sinais de difração se sobrepuseram, indicando pureza de fase. Entretanto, as amostras não apresentaram diferenças significativas nas intensidades dos sinais. Desse modo, o tratamento solvotérmico por 12 horas tornou-se suficiente para formação da estrutura metalorgânica UIO-66, pois com menor tempo de síntese proporciona menor custo de produção.

A isoterma de fisissorção $\mathrm{N}_{2}$ à $-196^{\circ} \mathrm{C}$, apresentada pela Figura 2 (b) é classificada pela IUPAC como tipo I, característica de sólidos microporosos, fato também comprovado observando a distribuição de tamanhos de poros obtida pelo método DFT. Este, indicou duas populações representativas de poro na estrutura do UIO-66, uma com 1,7 nm e a outra com $1,9 \mathrm{~nm}$. A área específica calculada pelo método BET foi de $1346,60 \mathrm{~m}^{2} \cdot \mathrm{g}^{-1}$, área de microporos de $1170,10 \mathrm{~m}^{2} \cdot \mathrm{g}^{-1}$, volume total de poros de $0,68 \mathrm{~cm}^{3} \cdot \mathrm{g}^{-1}$ e por fim o volume de microporos de $0,46 \mathrm{~cm}^{3} \cdot \mathrm{g}^{-1}$. Assim, os trabalhos de Wu et al. (2013), Cliffe et al. (2014) e Cavka et al. (2008) estão de acordo com os dados experimentais realizados.

Os resultados da adsorção de $\mathrm{CO}_{2}$ e $\mathrm{N}_{2}$, também como a relação entre as quantidades adsorvidas isentas de ativação térmica destes gases no material são apresentados na Figura 3 
(c). Sendo assim, em 1,0 bar de pressão relativa, o material adsorveu 1,6 mmol.g $\mathrm{g}^{-1}$ de $\mathrm{CO}_{2} \mathrm{e}$ 0,2 mmol.g ${ }^{-1}$ de $\mathrm{N}_{2}$. Desse modo, o UIO-66 adsorveu 43 vezes mais $\mathrm{CO}_{2}$ do que $\mathrm{N}_{2}$ e nas mesmas condições de pressão, a razão de adsorção é superior a 7. Portanto, o composto metalorgânico sintetizado pode ser aplicado no processo de separação e captura de $\mathrm{CO}_{2}$ da atmosfera.

\section{CONCLUSÃO}

É de suma importância que o avanço do conhecimento tente solucionar os problemas naturais ocasionados no planeta Terra. O composto metalorgânico UIO-66 sintetizado adsorve cerca de 43 vezes mais gás carbônico do que o gás inerte $\mathrm{N}_{2}$. Isso garante que o material possui alta capacidade de controle de poluição e processo de purificação de gases, permitindo que minimize os efeitos antrópicos de emissão de GEEs causado pelo avanço tecnológico.

\section{REFERÊNCIAS}

CAVKA, J. H.; JAKOBSEN, S.; OLSBYE, U.; GUILLOU, N.; LAMBERTI, C.; BORDIGA, S. E LILLERUD, K. P.. J. Am. Chem. Soc. 2008, 130, 13850-13851.

CLIFFE, M. J.; WAN, W.; ZOU, X.; CHATER, P. A.; KLEPPE, A. K.; TUCKER, M. G.; WILHELM, H.; FUNNELL, N. P.; COUDERT, F. X. E GOODWIN, A. L. Nat. Commun., 2014, 5 (4176), 1-9.

HOUGHTON, J. T.; JENKINS, G. J.; EPHRAUMS, J. J., Intergovernmental Panel on Climate Change, 1990. Disponível em: http://www.ipcc.ch. Acesso em: 15 de março de 2017.

O. M. YANGUI ET AL., Reticular Synthesis and the design of new materials, Nat., vol. 423, no. 6941, pp. 705-714, Jun, 2003.

WU, H.; CHUA, I. S.; KRUNGLEVICIUTE, V.; TYAGI, M.; CHEN, P.; YILDIRIM, T. E ZHOU, W.; J. Am. Chem. Soc.2013, 135, 10525-10532 